\title{
Evaluation of Oral Subchronic Toxicity of Soshiho-Tang Water Extract: The Traditional Herbal Formula in Rats
}

\author{
Mee-Young Lee, ${ }^{1}$ Chang-Seob Seo, ${ }^{1}$ In-Shik Shin, ${ }^{1}$ Young-Bum Kim, ${ }^{2}$ \\ Jung-Hoon Kim, ${ }^{1}$ and Hyeun-Kyoo Shin ${ }^{1}$ \\ ${ }^{1}$ Basic Herbal Research Group, Korea Institute of Oriental Medicine, Exporo 483, Yuseong-gu, Daejeon 305-811, Republic of Korea \\ ${ }^{2}$ Division of Nonclinical Studies, Korea Institute of Toxicology, P.O. Box 123, 19 Sinseongro, Yuseong-gu, \\ Daejeon 305-343, Republic of Korea
}

Correspondence should be addressed to Hyeun-Kyoo Shin; hkshin@kiom.re.kr

Received 4 October 2012; Accepted 20 February 2013

Academic Editor: Gaofeng Liu

Copyright (C) 2013 Mee-Young Lee et al. This is an open access article distributed under the Creative Commons Attribution License, which permits unrestricted use, distribution, and reproduction in any medium, provided the original work is properly cited.

Soshiho-tang (Xiao-chai-hu-tang in Chinese and Sho-saiko-to in Japanese) has been widely used for its various pharmacological effects, which include anti-inflammatory, antioxidant, antihepatic fibrosis, and antitumor properties. To evaluate the safety of Soshiho-tang water extract (SST), we tested its subchronic toxicity in male and female Crl:CD (SD) rats. Rats were orally treated with four different doses $(0,500,1000$, and $2000 \mathrm{mg} / \mathrm{kg} /$ day) of SST administered for 13 weeks. Mortality, clinical signs, body weight changes, food and water consumption changes, ophthalmology, urinalysis, hematological and biochemical parameters, gross findings, organ weights, and histological markers were monitored during the study. The SST treatment did not result in any toxicologically significant changes in mortality, clinical signs, body weights, food and water consumption, ophthalmoscopy, urinalysis, hematological and serum biochemical parameters, gross findings, organ weights, or histopathology. Histological analysis did not show any liver or kidney alteration. We concluded that the 13-week repeated oral administration of SST did not cause any adverse effects in rats at dosage levels of $\leq 2000 \mathrm{mg} / \mathrm{kg} /$ day. Under these experimental conditions, the no-observed-adverse-effect level was concluded to be $2000 \mathrm{mg} / \mathrm{kg} /$ day for both sexes.

\section{Introduction}

Medicinal herbs are used for the prevention and treatment of disease and have a long history. Because traditional herbal medicines have few side effects and are very effective, the consumption of these medicines has increased substantially in recent decades [1]. With increasing herbal medicine consumption, concerns have been raised over the lack of quality control and scientific evidence of the efficacy and safety of herbal medicine [2-4].

Soshiho-tang (Xiao-chai-hu-tang in Chinese and Shosaiko-to in Japanese) is frequently used for the treatment of liver disorders. It is composed of seven herbs: Bupleuri Radix, Scutellariae Radix, Ginseng Radix, Pinelliae Tuber, Glycyrrhizae Radix et Rhizoma, Zingiberis Rhizoma Crudus, and Zizyphi Fructus (Table 1). According to previous studies, Soshiho-tang exhibits various pharmacological properties including anti-inflammatory [5], antioxidant [6], immunomodulating [7], hepatoprotective [8], antihepatic fibrosis [9], and antitumor effects [10]. Although Soshihotang has various pharmacological properties, few scientific studies have investigated its safety and toxicity. Recently, the complexity of herbal prescriptions in general, and their inherent biological variations, was demonstrated; it is now necessary to evaluate their safety, efficacy, and quality [1]. However, the toxicity and quality control of herbal formulas to the public is becoming a problem because of the lack of scientific evidence about herbal formulas. Because few studies have explored the safety and toxicity of herbal formulas, public concern has been raised regarding their potential adverse effects [11].

The present study examined the safety of the oral use of SST for 13 weeks. The study was conducted in accordance with the guidelines established by the Organization for Economic 
Cooperation and Development (OECD, TG 408) [12] for the testing of chemicals and recent Good Laboratory Practice (GLP) Regulations.

\section{Materials and Methods}

2.1. Reagents and Materials. Liquiritin, baicalin, and glycyrrhizin were purchased from Wako Pure Chemical Industries, Ltd. (Osaka, Japan). The purity of each component was determined to be above $98 \%$ by high-performance liquid chromatography (HPLC) analysis. HPLC-grade reagents, methanol, acetonitrile, and water were obtained from J. T. Baker (Phillipsburg, NJ, USA). Glacial acetic acid was of analytical reagent grade, procured from Junsei (Tokyo, Japan). The materials used to form Soshiho-tang were purchased from Omniherb (Yeongcheon, Republic of Korea) and HMAX (Chungbuk, Republic of Korea). A voucher specimen (2008-KE26-1 KE26-7) was deposited at the Basic Herbal Medicine Research Group, Korea Institute of Oriental Medicine.

2.2. Preparation of Soshiho-Tang Water Extract (SST) and Sample Solutions. A decoction of Soshiho-tang was prepared in our laboratory from a mixture of chopped crude herbs (Table 1), extracted in distilled water at $100^{\circ} \mathrm{C}$ for $2 \mathrm{~h}$. The solution was evaporated to dryness, and freeze-dried (yield: $22.9 \%$ ). Lyophilized Soshiho-tang extract (200 mg) was dissolved in distilled water $(20 \mathrm{~mL})$. The solution was then diluted tenfold with distilled water. The solution was filtered using a SmartPor GHP syringe filter $(0.2 \mu \mathrm{m}$, Woongki Science, Seoul, Republic of Korea).

2.3. Preparation of Standard Solutions. A methanol standard stock solution containing liquiritin, baicalin, and glycyrrhizin (all $1.0 \mathrm{mg} / \mathrm{mL}$ ) was prepared and diluted to the appropriate concentration range for the establishment of calibration curves. The calibration curves were calculated using the peak areas of standard solution in the range $3.91-250.00 \mu \mathrm{g} / \mathrm{mL}$ for the three compounds.

2.4. HPLC Analysis of SST. A Shimadzu LC-20A HPLC system (Shimadzu Co., Kyoto, Japan) consisting of a solvent delivery unit, an online degasser, a column oven, an autosampler, and a PDA detector was used. The data processor employed LCsolution software (version 1.24). The analytical column used was a Gemini C18 $(250 \times 4.6 \mathrm{~mm}$; particle size $5 \mu \mathrm{m}$, Phenomenex, Torrance, CA, USA). The mobile phases consisted of solvent A $(1.0 \%$, v/v, aqueous acetic acid) and solvent $B$ (acetonitrile with $1.0 \%, \mathrm{v} / \mathrm{v}$, acetic acid). The gradient flow was as follows: $(\mathrm{A}) /(\mathrm{B})=$ $85 / 15(0 \mathrm{~min}) \rightarrow(\mathrm{A}) /(\mathrm{B})=60 / 40(20 \mathrm{~min}) \rightarrow(\mathrm{A}) /(\mathrm{B})$ $=45 / 55(40 \mathrm{~min}) \rightarrow(\mathrm{A}) /(\mathrm{B})=0 / 100$ (50 min; hold for $5 \mathrm{~min}) \rightarrow(\mathrm{A}) /(\mathrm{B})=85 / 15$ (55 min; hold for $15 \mathrm{~min})$. The column temperature was maintained at $30^{\circ} \mathrm{C}$. The analysis was carried out at a flow rate of $1.0 \mathrm{~mL} / \mathrm{min}$ with PDA detection at 254 and $275 \mathrm{~nm}$. The injection volume was $10 \mu \mathrm{L}$.
TABle 1: Composition of Soshiho-tang.

\begin{tabular}{lccc}
\hline Latin name & $\begin{array}{c}\text { Amount } \\
(\mathrm{g})\end{array}$ & $\begin{array}{c}\text { Company of } \\
\text { purchase }\end{array}$ & Source \\
\hline Bupleuri Radix & 11.25 & HMAX & China \\
Scutellariae Radix & 7.5 & HMAX & $\begin{array}{c}\text { Jeongseon, Korea } \\
\text { Pinelliae Tuber }\end{array}$ \\
$\begin{array}{l}\text { Ginseng Radix } \\
\text { Alba }\end{array}$ & 3.75 & HMAX & China \\
$\begin{array}{l}\text { Zizyphi Fructus } \\
\text { Zingiberis }\end{array}$ & 3.75 & Omniherb & Yeongcheon, Korea \\
$\begin{array}{l}\text { Rhizoma Crudus } \\
\text { Glycyrrhizae Radix } \\
\text { et Rhizoma }\end{array}$ & 3.75 & Omniherb & Yeongcheon, Korea \\
\hline Total & 1.875 & HMAX & China \\
\hline
\end{tabular}

2.5. Experimental Animals and Design. Forty-eight Crl:CD (SD) rats of each sex were obtained from a specific pathogenfree facility at Orient Bio Co. (Seoul, Republic of Korea) at 5 weeks of age and used after a week of quarantine and acclimatization. This study was approved by Korea Institute of Oriental Medicine Institutional Animal Care and Use Committee and was performed at the Korea Institute of Toxicology (Daejeon, Republic of Korea) and conducted according to the guidance of the Institutional Animal Care and Use Committee in Korea Institute of Toxicology (KRICT) (accredited by AAALAC International, 1998) under the GLP Regulations for Nonclinical Laboratory Studies.

Healthy male and female rats were randomly assigned to four experimental groups: SST 0, 500, 1000, and $2000 \mathrm{mg} / \mathrm{kg} /$ day groups and a vehicle control group. Each experimental group consisted of 10 rats of each sex.

In the previous 4-week repeated-dose study of SST, no treatment-related toxic changes were observed at the highest dose of $2000 \mathrm{mg} / \mathrm{kg} /$ day. Therefore, the highest dose level of $2000 \mathrm{mg} / \mathrm{kg} / \mathrm{day}$, with a common ratio of 2 , was chosen for this 13-week repeated-dose study. Oral administration was selected in the present study, because the oral route is the clinically intended route for the administration of Soshihotang. The SST was suspended in distilled water and was freshly prepared daily before treatment for 13 weeks. The daily application volume $(10 \mathrm{~mL} / \mathrm{kg}$ of body weight) of SST was calculated in advance, based on the most recently recorded body weights of individual animals.

2.6. Clinical Observations and Mortality. All animals were observed twice daily and clinical signs and mortality (if any) were recorded. Body weight and food and water intake were monitored weekly. After a one-week acclimation period, rats were observed twice daily (before and after the daily treatment) for the presence of common symptoms and mortality. Food and water consumption was recorded once before treatment onset and approximately once a week thereafter by measuring the difference between the amounts provided, and amounts remaining on the following day. This was regarded as daily consumption. External eye examinations were performed during the pretest period and all animals in each 


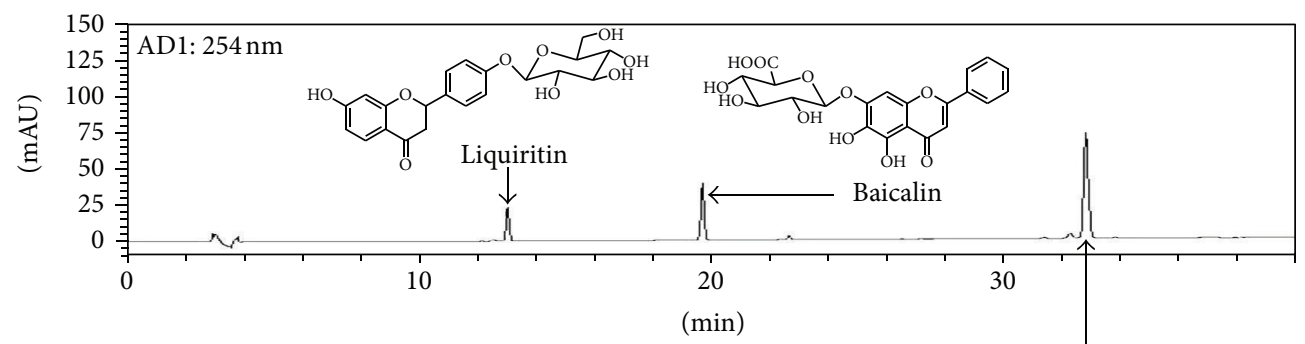

(a) $254 \mathrm{~nm}$

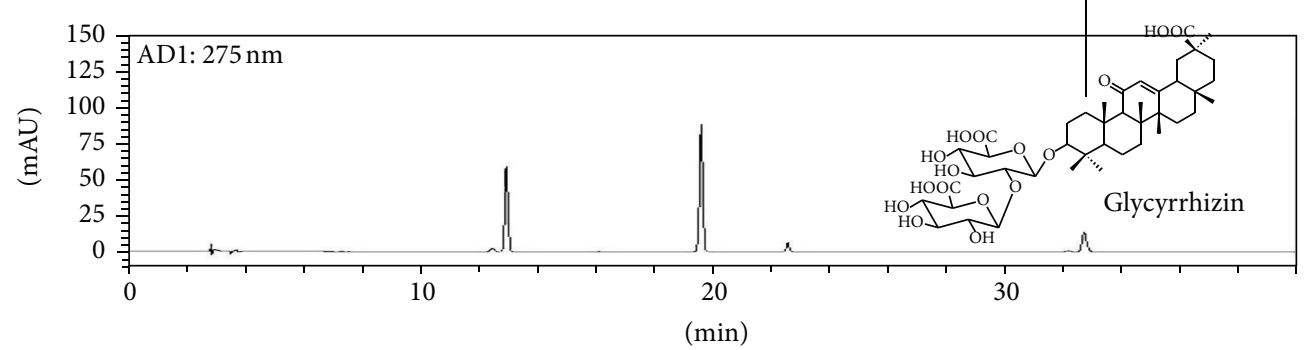

(b) $275 \mathrm{~nm}$

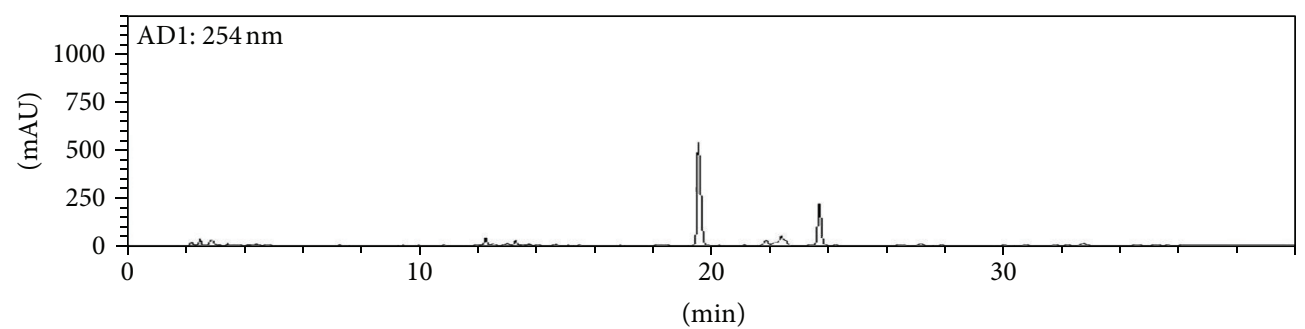

(c) $254 \mathrm{~nm}$

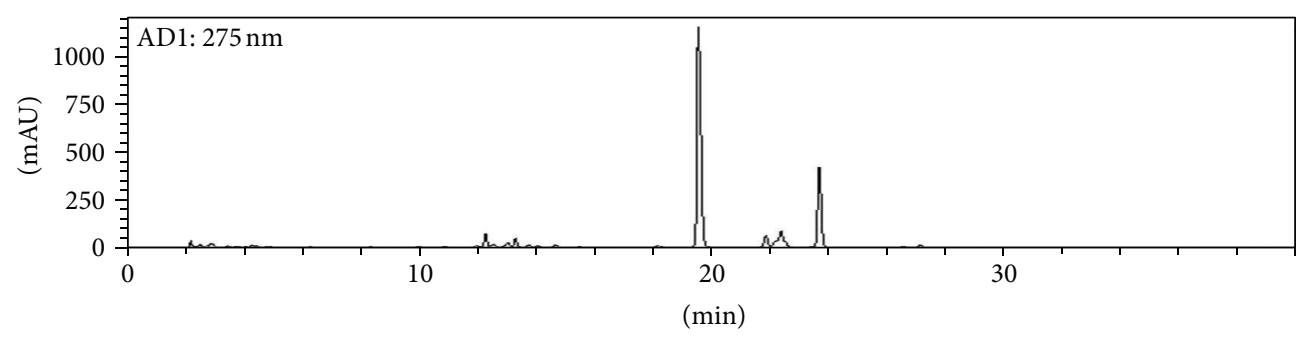

(d) $275 \mathrm{~nm}$

FIGURE 1: HPLC chromatogram of the standard mixtures ((a) and (b)) and SST samples ((c) and (d)).

group were briefly examined via both external and fundus examination using an indirect binocular ophthalmoscope (IO-H, Neitz Instruments Co., Japan) during the last week of dosing. Mortality and clinical signs were recorded using the PATH/TOX SYSTEM (version 4.2.2).

2.7. Urinalysis, Hematology, and Serum Biochemistry. Fresh urine was collected from all animals, and urinalysis was conducted to assess urine volume, specific gravity, $\mathrm{pH}$, and the levels of protein, ketone bodies, glucose, bilirubin, nitrite, urobilinogen, color, cast, epithelial cells, erythrocytes, leucocytes, and occult blood using a Multistix 10SG instrument (Bayer, USA) and a urine chemical analyzer (CliniTek 500, Bayer, USA).

Fresh blood samples were analyzed to determine the red blood cell count, hemoglobin concentration, hematocrit level, mean corpuscular cell volume, mean corpuscular cell hemoglobin, mean corpuscular cell hemoglobin concentration, platelet count, white blood cell count (WBC), differential WBC count, reticulocyte count, prothrombin time, and activated partial thromboplastin time. All parameters were measured using an ADVIA 120 Hematology System (Bayer, USA). In addition, prothrombin time and activated partial thromboplastin time were determined from blood samples treated with $3.2 \%$ sodium citrate, using a coagulometer (Coagrez-100s, Japan).

Serum biochemistry parameters were examined, including the levels of blood urea nitrogen (BUN), alanine aminotransferase (ALT), aspartate aminotransferase (AST), alkaline phosphatase (ALP), creatinine (CREA), glucose (GLU), total cholesterol (TCHO), albumin/globulin ratio $(\mathrm{A} / \mathrm{G})$, 
TABLE 2: Regression data, linear range, correlation coefficient, and stability for three compounds $(n=3)$.

\begin{tabular}{lcccccc}
\hline Compound & Linear range $(\mu \mathrm{g} / \mathrm{mL})$ & Slope & Intercept & Correlation coefficient $\left(R^{2}\right)$ & \multicolumn{2}{c}{ Stability (RSD (\%)) } \\
Retention time & Peak area \\
\hline Liquiritin & $3.91-250.00$ & 20031 & -19996 & 0.9997 & 0.21 & 3.09 \\
Baicalin & $3.91-250.00$ & 38806 & -79724 & 0.9993 & 1.12 \\
Glycyrrhizin & $3.91-250.00$ & 8959.4 & -15143 & 0.9996 & 1.10 & 1.05 \\
\hline
\end{tabular}

TABLE 3: Contents of three components in the SST for 13 weeks by HPLC $(n=3)$.

\begin{tabular}{lccccccccc}
\hline \multirow{2}{*}{ Compound } & \multicolumn{3}{c}{ 0 week } & \multicolumn{3}{c}{1 week } & \multicolumn{3}{c}{13 week } \\
& Mean $(\mathrm{mg} / \mathrm{g})$ & $\mathrm{SD}$ & RSD $(\%)$ & Mean $(\mathrm{mg} / \mathrm{g})$ & SD & RSD (\%) & Mean (mg/g) & SD & RSD (\%) \\
\hline Liquiritin & 2.71 & 0.011 & 0.418 & 2.60 & 0.014 & 0.534 & 2.56 & 0.010 & 0.399 \\
Baiclin & 61.58 & 0.022 & 0.036 & 58.02 & 0.197 & 0.339 & 58.01 & 0.061 & 0.105 \\
Glycyrrhizin & 2.33 & 0.003 & 0.113 & 2.44 & 0.012 & 0.486 & 2.45 & 0.021 & 0.856 \\
\hline
\end{tabular}

total protein (TP), albumin (ALB), creatine kinase (CK), triglycerides (TG), total bilirubin (TBIL), phospholipids (PL), calcium $(\mathrm{Ca})$, inorganic phosphorus (IP), chloride $(\mathrm{Cl})$, sodium $(\mathrm{Na})$, and potassium $(\mathrm{K})$.

2.8. Necropsy. Following blood collection, the organs (brain, pituitary gland, adrenal gland, liver, spleen, kidneys, heart, thymus, lungs, salivary glands, thyroid glands, testes, epididymides, seminal vesicles, prostate, uterus, and ovaries) were removed, weighed, and examined macroscopically. The absolute weight was measured and the relative organ weight (percentage of body weight) was calculated.

2.9. Histopathological Examination. The testes and epididymides were fixed with Bouin's solution. The following samples were fixed using a 10\% formalin solution: kidneys, urinary bladder, liver, heart, spleen, thymus, salivary glands, aorta, pancreas, tongue, skeletal muscle, sciatic nerve, brain, thoracic SC, eyes and optic nerve, lungs, trachea, thyroid, parathyroid, adrenal gland, mandibular lymph node, the Harderian glands, esophagus, stomach, duodenum, jejunum, ileum, cecum, colon, rectum, mesenteric lymph node skin, mammary gland, sternum/marrow, femur/marrow, testes, epididymides, prostate, seminal vesicle, ovaries, uterus/cervix, and vagina. All samples were sectioned and stained with hematoxylin and eosin.

2.10. Statistical Analyses. Data collected during the study were examined for variance homogeneity using Bartlett's test. One-way ANOVA was performed at $\alpha=0.05$ in cases in which Bartlett's test indicated no significant deviations from variance homogeneity. When significance was noted, a multiple comparison test (Dunnett's test) was used to determine which pairs of groups were significantly different. In cases in which significant deviations from variance homogeneity were observed, a nonparametric comparison test (KruskalWalli's test) was performed. When a significant difference was observed in the Kruskal-Wallis test, Dunn's rank sum test was used to determine the specific pairs. Statistical analyses were performed using the PATH/TOX SYSTEM (version 4.2.2, Xybion Medical Systems Corporation, USA) and the SAS program (version 9.2). The level of significance was set at $P<0.05$ or 0.01 . Because treatment-related animal deaths were not observed, $\mathrm{LD}_{50}$ values were not measured.

\section{Results}

3.1. Linearity, Range, Limit of Detection (LOD), and Limit of Quantification (LOQ). Calibration curves of liquiritin, baicalin, and glycyrrhizin were obtained using standard solutions. The coefficients $\left(R^{2}\right)$ of the calibration curves for the three constituents were $\geq 0.9993$ (Table 2). LOD and LOQ were determined based on signal-to-noise $(\mathrm{S} / \mathrm{N})$ ratios of 3 and 10, respectively. The LOD and LOQ values were 0.09 and $0.29 \mu \mathrm{g} / \mathrm{mL}$ for liquiritin, 0.41 and $1.37 \mu \mathrm{g} / \mathrm{mL}$ for baicalin, and 0.21 and $0.70 \mu \mathrm{g} / \mathrm{mL}$ for glycyrrhizin.

3.2. HPLC Analysis of SST. Our analysis method was applied to the simultaneous determination of three compounds in SST: liquiritin, baicalin, and glycyrrhizin. The retention times of the three compounds were 12.99, 19.64, and $32.71 \mathrm{~min}$ for liquiritin, baicalin, and glycyrrhizin, respectively. The stability test was analyzed using the sample solution at 0,1 , $2,5,7$, and 10 days. The relative standard deviation values of retention time and peak area were within $1.12 \%$ and $3.09 \%$, respectively (Table 2 ). These results suggest that the solution was stable for at least 10 days. Figure 1 shows chromatograms of reference components and SST, with detection of eluents at 254 and $275 \mathrm{~nm}$. The concentrations of the three components identified in SST were $2.33-61.58 \mathrm{mg} / \mathrm{g}$. These results are summarized in Table 3.

3.3. Mortality and Clinical Signs. There was no mortality attributed to any effect of SST during the 13 weeks of drug administration. No SST treatment-related clinical signs were detected, with the exception of loss of fur, bite wounds, scratch wounds, eye discharge, and scabs.

3.4. Body Weight and Food Consumption. There were no significant differences in body weight (Figures 2(a) and 2(b)) or food consumption between control and treatment groups. 


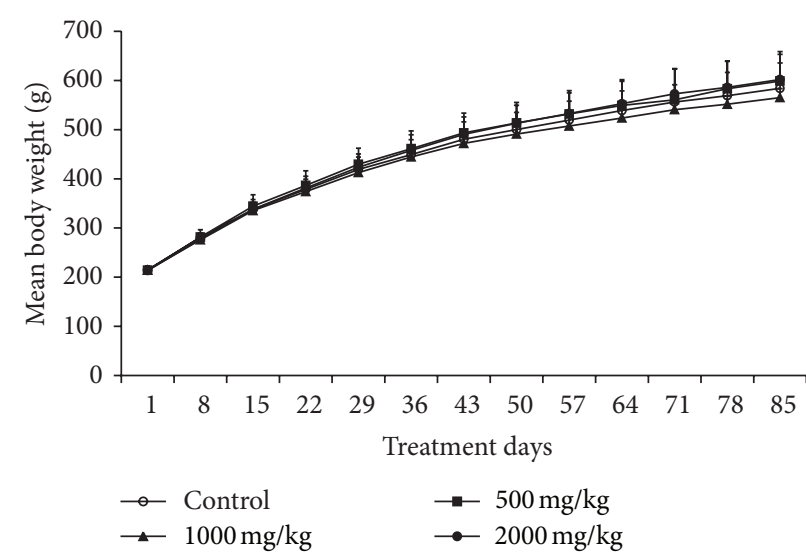

(a) Male

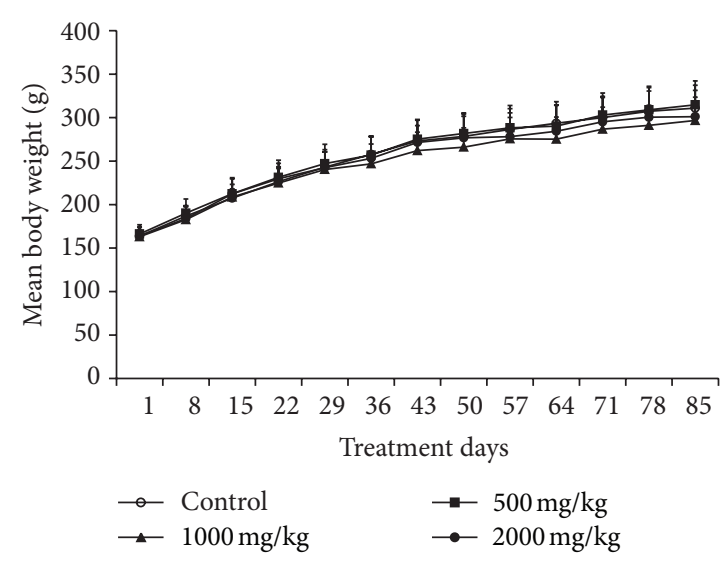

(b) Female

Figure 2: Mean body weight changes in male (a) and female (b) rats treated with SST at dose levels of 0 (०), 500 (घ), $1000(\mathbf{\Delta})$, and $2000(\bullet)$ $\mathrm{mg} / \mathrm{kg} /$ day for 13 weeks. Data are presented as mean values $\pm \mathrm{SD}$.

TABLE 4: Urinalysis values with SST for 13 weeks.

\begin{tabular}{|c|c|c|c|c|c|c|c|c|}
\hline \multirow{2}{*}{ Parameters } & \multicolumn{4}{|c|}{ Male } & \multicolumn{4}{|c|}{ Female } \\
\hline & Control & $500 \mathrm{mg} / \mathrm{kg}$ & 1000 mg/kg & $2000 \mathrm{mg} / \mathrm{kg}$ & Control & $500 \mathrm{mg} / \mathrm{kg}$ & $1000 \mathrm{mg} / \mathrm{kg}$ & $2000 \mathrm{mg} / \mathrm{kg}$ \\
\hline Volume (mL) & $18 \pm 6.8$ & $17 \pm 7.0$ & $15 \pm 7.3$ & $19 \pm 5.2$ & $9 \pm 4.2$ & $11 \pm 7.3$ & $10 \pm 9.1$ & $8 \pm 3.4$ \\
\hline SG & $1.08 \pm 0.0059$ & $1.02 \pm 0.0058$ & $1.02 \pm 0.0005$ & $1.01 \pm 0.0041$ & $1.02 \pm 0.0058$ & $1.01 \pm 0.0035$ & $1.02 \pm 0.0081$ & $1.02 \pm 0.0071$ \\
\hline $\mathrm{pH}$ & $7.0 \pm 0.28$ & $7.0 \pm 0.16$ & $6.8 \pm 0.26$ & $7.0 \pm 0.16$ & $6.7 \pm 0.26$ & $6.9 \pm 0.21$ & $6.5 \pm 0.41$ & $6.8 \pm 0.26$ \\
\hline URO (E.U./dL) & $0.2 \pm 0.00$ & $0.2 \pm 0.00$ & $0.2 \pm 0.00$ & $0.2 \pm 0.00$ & $0.2 \pm 0.00$ & $0.2 \pm 0.00$ & $0.2 \pm 0.00$ & $0.2 \pm 0.00$ \\
\hline
\end{tabular}

Also, there was no clear food consumption in SST-treated groups compared with control group (data not shown).

3.5. Ophthalmological Examination and Urinalysis. There were no abnormal ophthalmologic findings among the SSTtreated groups compared with each sex of the control group in the present study (data not shown). There were no significant changes in urinalysis results in any of the SST-treated groups compared with each sex of the control group (Table 4).

3.6. Hematology. The results of the hematological examination are shown in Table 5. No treatment-related changes in hematological parameters were observed in the present study. A prothrombin time delay was observed in the $2000 \mathrm{mg} / \mathrm{kg} /$ day male groups.

3.7. Serum Biochemistry. The results of the examination of serum biochemical values in the SST-treated and control groups are shown in Table 6 . In the male $1000 \mathrm{mg} / \mathrm{kg} / \mathrm{day}$ group, the levels of TBIL were significantly decreased. No other toxic-related serum biochemical value changes were observed in any group.

3.8. Relative Organ Weight. The results of relative organ weights are shown in Table 7. There were no significant differences related to SST treatment in the relative organ weight of male or female rats. In females, the relative kidney weight was significantly increased in the 1000 and $2000 \mathrm{mg} / \mathrm{kg} /$ day groups, and the relative liver and heart weights were significantly increased in the $2000 \mathrm{mg} / \mathrm{kg} /$ day group.

3.9. Histopathology. No treatment-related histopathology findings were observed after 13 weeks of SST treatment, and there were no histologic correlates for the organ weight changes (data not shown). Histopathological changes included minimal cardiomyopathy of the heart and foamy macrophages of the lungs in the male $2000 \mathrm{mg} / \mathrm{kg} /$ day group, and genital organs and estrus cycles were increased in the female group compared with the control group. These changes were not considered to be treatment related, because these microscopic changes are commonly observed in untreated laboratory animals and the incidence and severity were comparable between the treated and control animals.

Histopathological features of the kidney (Figure 3(A)) and liver (Figure 3(B)) in the control group and the highest dosage SST-treated groups showed normal structure.

\section{Discussion}

Herbal medicines have become increasingly popular in modern societies around the globe, and many research projects have conducted the studies on herbal medicine's pharmacological properties to establish its scientific evidence. Evidence of therapeutic materials is assessed throughout various sources including toxicity, pharmacological properties, clinical trials, and systematic reviews [13]. Traditional herbal medicine is the most important part of 
TABLE 5: Hematological values of rats treated orally with SST for 13 weeks.

\begin{tabular}{|c|c|c|c|c|c|c|c|c|}
\hline \multirow{2}{*}{ Parameters } & \multicolumn{4}{|c|}{ Male } & \multicolumn{4}{|c|}{ Female } \\
\hline & Control & $500 \mathrm{mg} / \mathrm{kg}$ & 1000 mg/kg & $2000 \mathrm{mg} / \mathrm{kg}$ & Control & $500 \mathrm{mg} / \mathrm{kg}$ & $1000 \mathrm{mg} / \mathrm{kg}$ & $2000 \mathrm{mg} / \mathrm{kg}$ \\
\hline WBC $\left(\times 10^{3} / \mu \mathrm{L}\right)$ & $13.50 \pm 3.755$ & $11.19 \pm 3.405$ & $10.88 \pm 2.983$ & $11.46 \pm 2.415$ & $8.30 \pm 2.100$ & $8.61 \pm 2.266$ & $7.93 \pm 2.220$ & $8.84 \pm 2.155$ \\
\hline $\mathrm{RBC}\left(\times 10^{6} / \mu \mathrm{L}\right)$ & $9.13 \pm 0.353$ & $9.14 \pm 0.445$ & $9.38 \pm 0.349$ & $9.00 \pm 0.265$ & $8.59 \pm 0.312$ & $8.43 \pm 0.437$ & $8.44 \pm 0.383$ & $8.50 \pm 0.354$ \\
\hline $\mathrm{HGB}(\mathrm{g} / \mathrm{dL})$ & $16.2 \pm 0.77$ & $16.4 \pm 0.57$ & $16.6 \pm 0.64$ & $16.1 \pm 0.44$ & $16.0 \pm 0.38$ & $16.1 \pm 0.57$ & $16.2 \pm 0.77$ & $16.3 \pm 0.74$ \\
\hline $\operatorname{HCT}(\%)$ & $49.1 \pm 2.00$ & $50.1 \pm 1.62$ & $50.1 \pm 2.11$ & $48.6 \pm 1.17$ & $48.0 \pm 1.55$ & $47.7 \pm 1.99$ & $47.5 \pm 2.12$ & $48.0 \pm 1.91$ \\
\hline MCV (fL) & $53.8 \pm 1.72$ & $54.9 \pm 1.98$ & $53.4 \pm 1.45$ & $54.1 \pm 1.56$ & $55.9 \pm 1.31$ & $56.6 \pm 1.12$ & $56.3 \pm 2.37$ & $56.5 \pm 1.91$ \\
\hline $\mathrm{MCH}(\mathrm{pg})$ & $17.7 \pm 0.91$ & $18.0 \pm 0.84$ & $17.7 \pm 0.50$ & $17.9 \pm 0.72$ & $18.7 \pm 0.53$ & $19.1 \pm 0.54$ & $19.2 \pm 0.88$ & $19.2 \pm 0.74$ \\
\hline MCHC (g/dL) & $32.9 \pm 0.98$ & $32.8 \pm 0.56$ & $33.1 \pm 0.37$ & $33.1 \pm 0.61$ & $33.4 \pm 0.75$ & $33.8 \pm 0.74$ & $34.1 \pm 0.45$ & $34.0 \pm 0.84$ \\
\hline $\operatorname{PLT}\left(\times 10^{3} / \mu \mathrm{L}\right)$ & $1110 \pm 84.7$ & $1061 \pm 124.4$ & $1038 \pm 122.2$ & $1086 \pm 94.6$ & $1082 \pm 62.3$ & $1072 \pm 142.6$ & $1025 \pm 108.8$ & $1196 \pm 550.6$ \\
\hline Reticulocyte (\%) & $2.5 \pm 0.41$ & $2.3 \pm 0.33$ & $2.3 \pm 0.43$ & $2.3 \pm 0.39$ & $2.5 \pm 0.42$ & $2.5 \pm 0.29$ & $2.1 \pm 0.47$ & $2.8 \pm 0.98$ \\
\hline Neutrophils (\%) & $15.09 \pm 5.508$ & $16.58 \pm 5.953$ & $19.51 \pm 7.614$ & $17.27 \pm 5.569$ & $12.50 \pm 4.448$ & $13.24 \pm 4.517$ & $11.28 \pm 4.780$ & $12.42 \pm 4.247$ \\
\hline Lymphocytes (\%) & $79.2 \pm 5.78$ & $77.7 \pm 5.60$ & $74.8 \pm 8.29$ & $76.5 \pm 6.17$ & $81.8 \pm 4.52$ & $80.7 \pm 5.28$ & $82.5 \pm 4.97$ & $82.4 \pm 4.55$ \\
\hline Monocytes (\%) & $3.2 \pm 0.98$ & & & $3.3 \pm 0.74$ & $2.8 \pm 0.69$ & $3.2 \pm 0.85$ & $3.2 \pm 0.58$ & $2.6 \pm 0.64$ \\
\hline Eosinophils (\%) & $1.1 \pm 0.28$ & $1.2 \pm 0.40$ & $1.4 \pm 0.44$ & $1.2 \pm 0.29$ & $1.2 \pm 0.25$ & $1.3 \pm 0.60$ & $1.3 \pm 0.32$ & $1.1 \pm 0.33$ \\
\hline Basophils (\%) & $0.6 \pm 0.22$ & $0.8 \pm 0.22$ & $0.7 \pm 0.21$ & $0.8 \pm 0.23$ & $0.7 \pm 0.30$ & $0.6 \pm 0.28$ & $0.7 \pm 0.28$ & $0.6 \pm 0.26$ \\
\hline LUC (\%) & $0.9 \pm 0.31$ & $0.8 \pm 0.24$ & $0.8 \pm 0.22$ & $1.1 \pm 0.56$ & $1.0 \pm 0.22$ & $1.0 \pm 0.27$ & $1.0 \pm 0.22$ & $0.8 \pm 0.22$ \\
\hline PT (sec) & $15.9 \pm 1.05$ & $16.2 \pm 0.71$ & $16.8 \pm 1.20$ & $17.2 \pm 1.13^{*}$ & $15.5 \pm 0.78$ & $15.2 \pm 0.53$ & $16.1 \pm 1.77$ & $16.2 \pm 1.21$ \\
\hline APTT (sec) & $16.8 \pm 1.52$ & $17.1 \pm 0.79$ & $17.3 \pm 0.82$ & $17.1 \pm 0.87$ & $14.6 \pm 1.22$ & $14.4 \pm 0.99$ & $14.5 \pm 1.32$ & $14.3 \pm 1.50$ \\
\hline
\end{tabular}

${ }^{*}$ Significant differences from control group $(P<0.05)$.

TABLE 6: Serum biochemical values of rats treated orally with SST for 13 weeks.

\begin{tabular}{|c|c|c|c|c|c|c|c|c|}
\hline \multirow{2}{*}{ Parameters } & \multicolumn{4}{|c|}{ Male } & \multicolumn{4}{|c|}{ Female } \\
\hline & Control & $500 \mathrm{mg} / \mathrm{kg}$ & $1000 \mathrm{mg} / \mathrm{kg}$ & $2000 \mathrm{mg} / \mathrm{kg}$ & Control & $500 \mathrm{mg} / \mathrm{kg}$ & $1000 \mathrm{mg} / \mathrm{kg}$ & $2000 \mathrm{mg} / \mathrm{kg}$ \\
\hline (dL) & $137.4 \pm 44.22$ & $121.6 \pm 24.25$ & $111.5 \pm 20.60$ & $125.2 \pm 35.90$ & $155.3 \pm 27.24$ & $138.2 \pm 18.97$ & $128.8 \pm 29.05$ & $=21.23$ \\
\hline $\mathrm{g} / \mathrm{dL})$ & $6 \pm 1.45$ & $.4 \pm 1.31$ & $13.8 \pm 1.92$ & $14.7 \pm 1.02$ & $18.7 \pm 2.38$ & $16.0 \pm 1.95$ & $17.5 \pm 2.19$ & $17.1 \pm 2.32$ \\
\hline $\mathrm{ng} / \mathrm{dL})$ & $0.56 \pm 0.052$ & $5 \pm 0.061$ & $7 \pm 0.063$ & $56 \pm 0.052$ & $0.71 \pm 0.046$ & $0.69 \pm 0.050$ & .054 & .086 \\
\hline & $6.98 \pm$ & 28 & 90 & & & & & .584 \\
\hline $\operatorname{ALB}(\mathrm{g} / \mathrm{dL})$ & $4.49 \pm$ & $4.49 \pm$ & $4.40 \pm$ & & & & & $5.38 \pm 0.310$ \\
\hline A/G (ratio) & $1.82 \pm 0.149$ & $1.83 \pm 0.125$ & $1.81 \pm 0.151$ & $1.80 \pm 0.148$ & & & $2.06 \pm 0.086$ & $1.97 \pm 0.136$ \\
\hline TCHO (mg/dL) & $70.3 \pm 22.49$ & $71.8 \pm 12.37$ & & & & & $95.2 \pm 18.61$ & $91.3 \pm 24.44$ \\
\hline TG (mg/dL) & $55.4 \pm 22.90$ & $55.1 \pm 16.17$ & $50.6 \pm 14.86$ & $67.2 \pm 3$ & $60.7 \pm 27.67$ & $42.1 \pm 8.77$ & $47.3 \pm 10.10$ & $51.2 \pm 14.93$ \\
\hline $\mathrm{PL}(\mathrm{mg} / \mathrm{dL})$ & $102 \pm 22.7$ & $107 \pm 16.5$ & $96 \pm 15.7$ & $110 \pm 22.8$ & $169 \pm 38.3$ & $162 \pm 20.9$ & $170 \pm 25.9$ & $169 \pm 36.2$ \\
\hline AST (IU/L) & $124.9 \pm 29.29$ & $117.1 \pm 13.76$ & $122.3 \pm 18.48$ & $114.1 \pm 14.50$ & $116.6 \pm 34.14$ & $142.1 \pm 73.28$ & $138.1 \pm 29.01$ & $115.1 \pm 22.97$ \\
\hline & & $33.6 \pm 5$ & & $33.6 \pm$ & $32.5 \pm 10.83$ & $49.3 \pm 46.80$ & $49.5 \pm 14.82$ & $35.6 \pm 14.54$ \\
\hline TBIL (mg/dL) & $0.157 \pm 0.01$ & $0.141 \pm 0.01$ & $0.133 \pm 0.02^{*}$ & $0.149 \pm 0.01$ & $0.178 \pm 0.01$ & $0.183 \pm 0.02$ & $0.154 \pm 0.02$ & $0.192 \pm 0.03$ \\
\hline ALP (IU/L) & $214.1 \pm 29.52$ & $241.9 \pm 28.77$ & $241.2 \pm 40.68$ & $230.2 \pm 25.28$ & $124.2 \pm 34.46$ & & $137.5 \pm 46.11$ & $125.0 \pm 21.91$ \\
\hline CK (IU/L) & $623 \pm 197.7$ & $579 \pm 154.9$ & $622 \pm 162.4$ & $581 \pm 212.6$ & $550 \pm 244.5$ & $549 \pm 138.0$ & $534 \pm 209.3$ & $468 \pm 162.6$ \\
\hline $\mathrm{Ca}(\mathrm{mg} / \mathrm{dL})$ & $11.08 \pm 0.36$ & $11.22 \pm 0.37$ & $11.03 \pm 0.38$ & $11.49 \pm 0.45$ & $11.88 \pm 0.51$ & $11.83 \pm 0.36$ & $11.71 \pm 0.46$ & $12.30 \pm 0.49$ \\
\hline $\mathrm{IP}(\mathrm{mg} / \mathrm{dL})$ & $9.12 \pm 1.48$ & $9.13 \pm 0.60$ & $8.55 \pm 0.65$ & $9.29 \pm 0.65$ & $7.01 \pm 1.069$ & $7.13 \pm 1.190$ & $7.01 \pm 1.185$ & $7.95 \pm 1.101$ \\
\hline $\mathrm{Na}(\mathrm{mmol} / \mathrm{L})$ & & & $147 \pm 2.3$ & & $147 \pm 2.3$ & $146 \pm 1.1$ & $146 \pm 1.8$ & $147 \pm 1.5$ \\
\hline $\mathrm{K}(\mathrm{mmol} / \mathrm{L})$ & $8.26 \pm 2.20$ & $8.32 \pm 1.49$ & $7.43 \pm 1.27$ & $7.83 \pm 0.69$ & $6.81 \pm 0.765$ & $7.04 \pm 1.075$ & $7.22 \pm 1.294$ & $7.78 \pm 1.469$ \\
\hline $\mathrm{CI}(\mathrm{mmol} / \mathrm{L})$ & $101 \pm 0.7$ & $102 \pm 1.5$ & $102 \pm 1.5$ & $102 \pm 1.6$ & $104 \pm 1.4$ & $103 \pm 1.3$ & $104 \pm 1.0$ & $102 \pm 1.4$ \\
\hline
\end{tabular}

${ }^{*}$ Significant differences from control group $(P<0.05)$.

complementary and alternative medicine and has been practiced for thousands of years. Although there are many traditional herbal medicines available, and some have been verified by clinical trials, their efficacy and safety are still questioned by consumers [14].
Some traditional herbal preparations in Korea and Japan are officially recognized as approved ethical drugs, and, in some cases, are covered by the National Health Insurance Program. Therefore, to confirm the safety of SST, the present study assessed its repeated-dose oral toxicity for 13 weeks in 


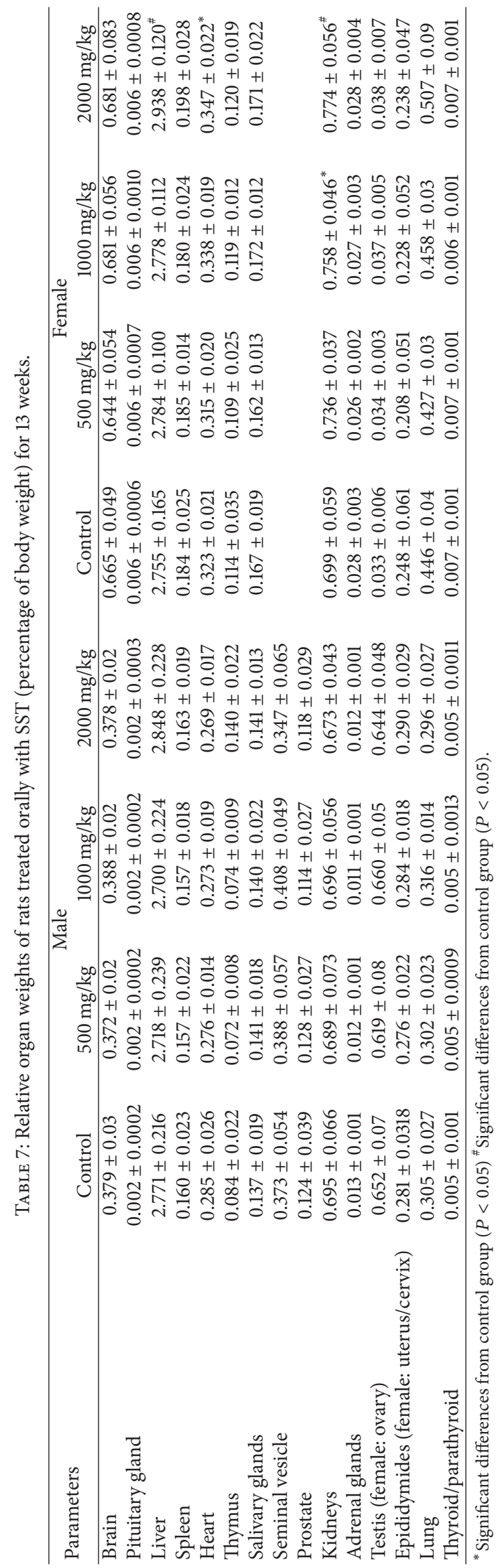




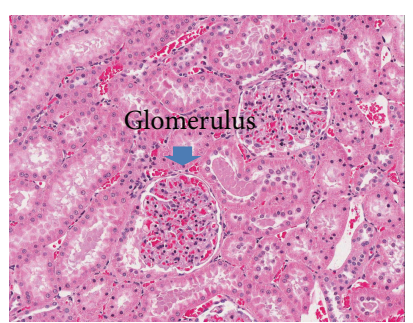

(a)

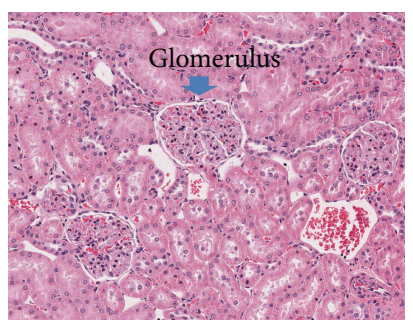

(c)

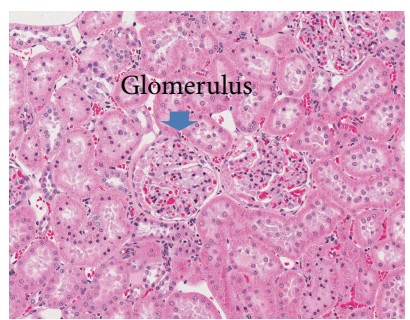

(b)

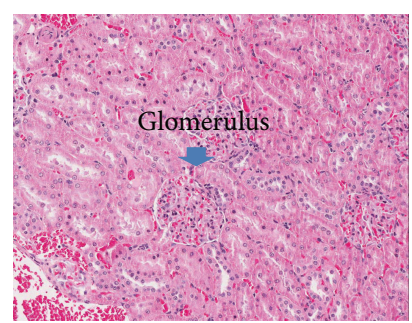

(d)

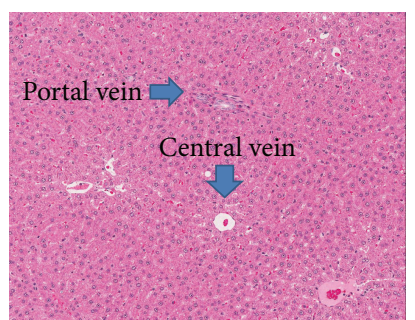

(a)

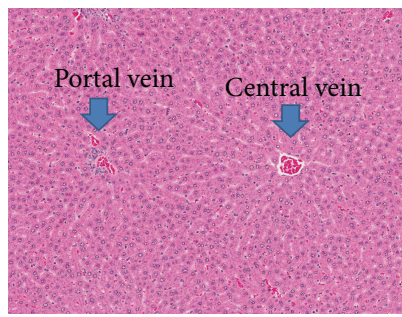

(c)

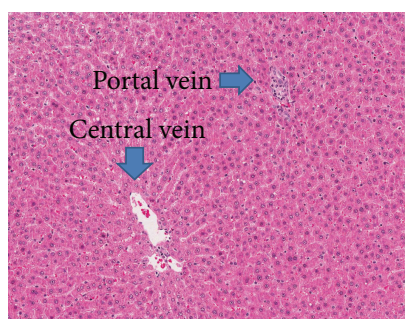

(b)

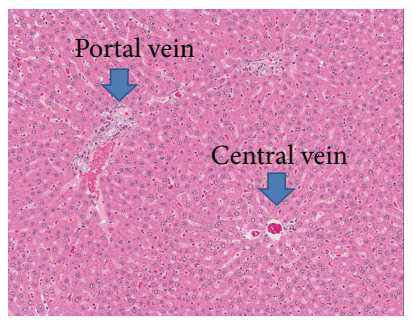

(d)

(A)

(B)

Figure 3: Histopathological findings in the kidney (A) and liver (B). (A) (a) Control male group, (b) $2000 \mathrm{mg} / \mathrm{kg} / \mathrm{day}$ SST-treated male group, (c) control female group, and (d) $2000 \mathrm{mg} / \mathrm{kg} /$ day SST-treated female group. H\&E stain; magnification, 200x.

female and male Crl:CD (SD) rats. The mortality and changes in body weight, food consumption, clinical signs, urinalysis, ophthalmological examination, hematology, serum biochemistry, gross observation, organ weight, and histopathology were monitored in accordance with the KFDA and OECD guidelines. Overall, SST was not associated with adverse effects in doses up to $2000 \mathrm{mg} / \mathrm{kg} /$ day administered for up to 13 weeks in both sexes.

Herbal medicine, a mixture of several herbs are considered to decrease its toxicity and enhance or prolong the pharmacological effects of any component. Toxicity assessment of SST has been studied in Japan. Previous study demonstrated that administration of SST did not cause any adverse effects at $1000 \mathrm{mg} / \mathrm{kg} /$ day [15]. However, dose of SST in previous study was comparatively lower than that used in our study, and toxicity study has been conducted under non-GLP conditions. Therefore, the present study has been conducted to clarify the safety of SST at GLP Regulations.

Clinical signs of salivation were observed in female $(n=$ $10)$ and male $(n=2) 2000 \mathrm{mg} / \mathrm{kg} /$ day SST-treated rats. However, these were not considered to be related to SST treatment because incidence was low and no dose-response relationship was observed.

There were no changes in body weight, food consumption, urinalysis, or ophthalmology. No abnormal changes were detected regarding hematological and serum biochemical parameters up to the highest dosage of SST, $2000 \mathrm{mg} / \mathrm{kg} / \mathrm{day}$; the changes in both sexes of treated rats were comparable to the changes in both sexes of control group rats.

Statistically significant increases in relative liver, kidney, and heart weights were observed in female rats treated with SST. However, these changes were not correlated with the
SST dosage and were within the normal range. Moreover, no gross pathological findings or histopathological changes were observed. Therefore, these changes in body weight were not considered to be SST-induced abnormalities.

Histopathological findings showed cardiomyopathy of the heart and foamy macrophages in the lungs in the male $2000 \mathrm{mg} / \mathrm{kg} /$ day rats. In the female $2000 \mathrm{mg} / \mathrm{kg} /$ day rats there was an increase in the estrus cycle compared with the control group. However, there were no histopathological findings for the ovaries or uterus. Although histopathological lesions were sporadically observed in the organs in male and female SSTtreated rats, the degree and incidence were similar to those of the control groups. Moreover, these findings are commonly observed in normal rats [16-18]. Therefore, it is reasonable to conclude that they were of little toxicological significance.

In conclusion, repeated oral dose administration of SST to SD rats for 13 weeks did not cause any adverse effects in rats of either sex, up to and including doses of $2000 \mathrm{mg} / \mathrm{kg} /$ day. Thus, the no-observed-adverse-effect level was concluded to be $2000 \mathrm{mg} / \mathrm{kg} /$ day for male and female rats.

\section{Conflict of Interests}

The authors declared that they have no conflict of interests.

\section{Authors' Contribution}

M.-Y. Lee and C.-S. Seo equally contributed to this work.

\section{Acknowledgment}

This study was part of a project (Evidence-based Medicine for Herbal Formulas, K11030) funded by the Herbal Medicine 
EBM Research Center of the Korea Institute of Oriental Medicine.

\section{References}

[1] L. S. Castro, F. F. Perazzo, and E. L. Maistro, "Genotoxicity testing of Ambelania occidentalis (Apocynaceae) leaf extract in vivo," Genetics and Molecular Research, vol. 8, no. 2, pp. 440447, 2009.

[2] F. Firenzuoli and L. Gori, "Herbal medicine today: clinical and research issues," Evidence-based Complementary and Alternative Medicine, vol. 4, supplement 1, pp. 37-40, 2007.

[3] L. B. Seeff, "Herbal hepatotoxicity," Clinics in Liver Disease, vol. 11, no. 3, pp. 577-596, 2007.

[4] J. L. Tang, B. Y. Liu, and K. W. Ma, "Traditional Chinese medicine," The Lancet, vol. 372, no. 9654, pp. 1938-1940, 2008.

[5] M. Kusunose, B. Qiu, T. Cui et al., "Effect of Sho-saiko-to extract on hepatic inflammation and fibrosis in dimethylnitrosamine induced liver injury rats," Biological and Pharmaceutical Bulletin, vol. 25, no. 11, pp. 1417-1421, 2002.

[6] G. Shiota, Y. Maeta, T. Mukoyama et al., "Effects of Sho-saikoto on hepatocarcinogenesis and 8-hydroxy-2' -deoxyguanosine formation," Hepatology, vol. 35, no. 5, pp. 1125-1133, 2002.

[7] M. H. Chen, J. C. Chen, C. C. Tsai et al., "The role of TGF- $\beta 1$ and cytokines in the modulation of liver fibrosis by Sho-saiko-to in rat's bile duct ligated model," Journal of Ethnopharmacology, vol. 97, no. 1, pp. 7-13, 2005.

[8] Z. Taira, K. Yabe, Y. Hamaguchi et al., "Effects of Sho-saikoto extract and its components, Baicalin, baicalein, glycyrrhizin and glycyrrhetic acid, on pharmacokinetic behavior of salicylamide in carbon tetrachloride intoxicated rats," Food and Chemical Toxicology, vol. 42, no. 5, pp. 803-807, 2004.

[9] M. H. Chen, J. C. Chen, C. C. Tsai et al., "Sho-saiko-to prevents liver fibrosis induced by bile duct ligation in rats," The American Journal of Chinese Medicine, vol. 32, no. 2, pp. 195-207, 2004.

[10] K. Zhu, I. Fukasawa, M. Furuno et al., "Inhibitory effects of herbal drugs on the growth of human ovarian cancer cell lines through the induction of apoptosis," Gynecologic Oncology, vol. 97, no. 2, pp. 405-409, 2005.

[11] M. Y. Lee, C. S. Seo, I. S. Shin et al., "Toxicological evaluation of Gumiganghwaltang aqueous extract in Crl:CD (SD) rats: 13 weeks oral gavage studies," Regulatory Toxicology and Pharmacology, vol. 62, no. 3, pp. 553-560, 2012.

[12] Organization for Economic Cooperation and Development (OECD), Guideline for the Testing of Chemical TG No. 408. Repeated Dose 90-day Oral Toxicity Study in Rodents, 2013, http://www.oecd-ilibrary.org/environment/test-no-408repeated-dose-90-day-oral-toxicity-study-in-rodents 9789264070707-en.

[13] D. M. Eddy, "Evidence-based medicine: a unified approach," Health Affairs, vol. 24, no. 1, pp. 9-17, 2005.

[14] C. W. Cheng, Z. X. Bian, and T. X. Wu, "Systematic review of Chinese herbal medicine for functional constipation," World Journal of Gastroenterology, vol. 15, no. 39, pp. 4886-4895, 2009.

[15] S. Minematsu, J. E. Atkinson, H. F. Bolte, H. Sakai, and Y. Fujii, "A subchronic (3-month) oral toxicity study of Tsumura Shosaiko-to (TJ-9) in the rat via oral gavage administration with a 4-week recovery period," Pharmacometrics, vol. 43, no. 1, pp. 19-42, 1992.

[16] G. Boorman, S. Eustis, M. Elwell et al., Pathology of the Fischer Rat, Reference and Atlas Academic Press, San Diego, Calif, USA, 1990.
[17] W. M. Haschek and C. G. Rousseaux, Fundamentals of Toxicologic Pathology, Academic Press, San Diego, Calif, USA, 1998.

[18] J. C. Kim, D. H. Shin, S. H. Kim et al., "Subacute toxicity evaluation of a new camptothecin anticancer agent CKD602 administered by intravenous injection to rats," Regulatory Toxicology and Pharmacology, vol. 40, no. 3, pp. 356-369, 2004. 


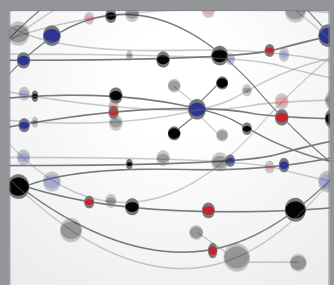

The Scientific World Journal
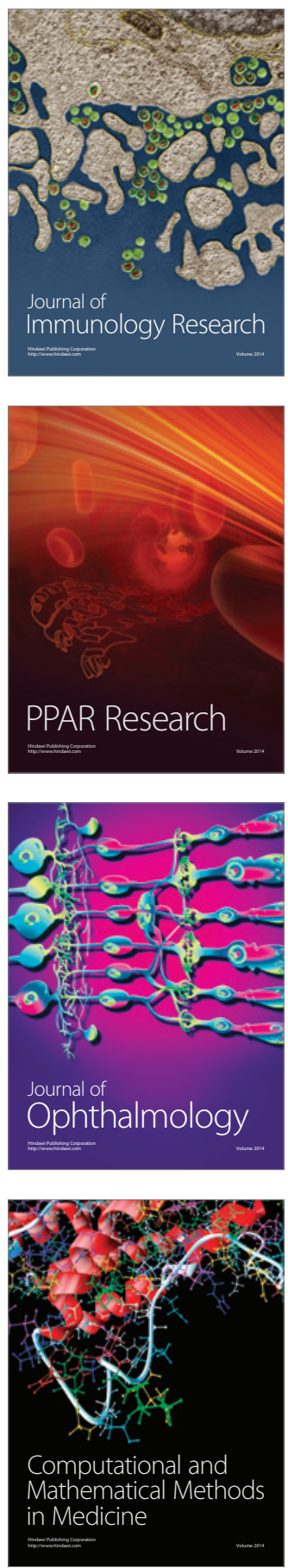

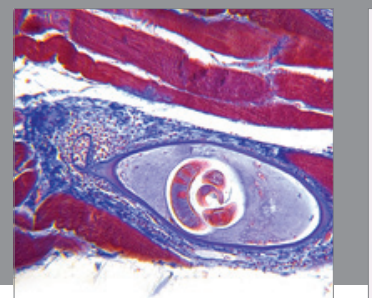

Gastroenterology

Research and Practice
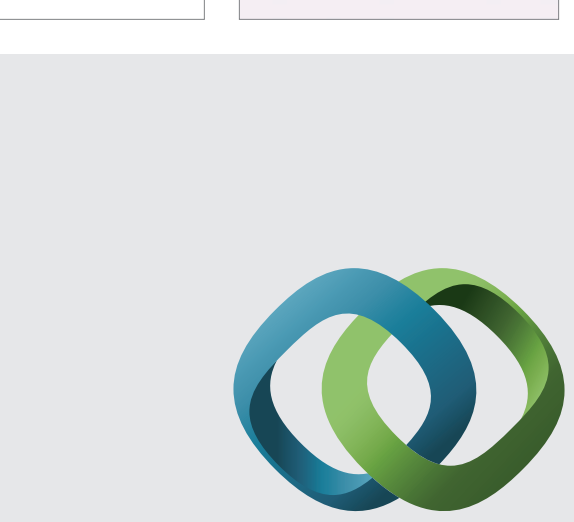

\section{Hindawi}

Submit your manuscripts at

http://www.hindawi.com
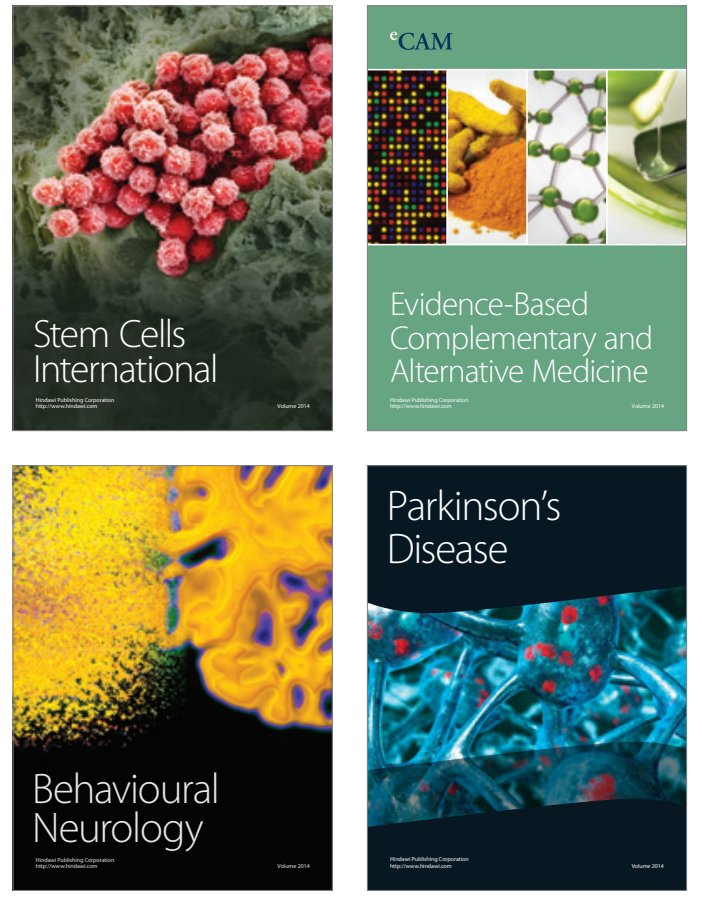
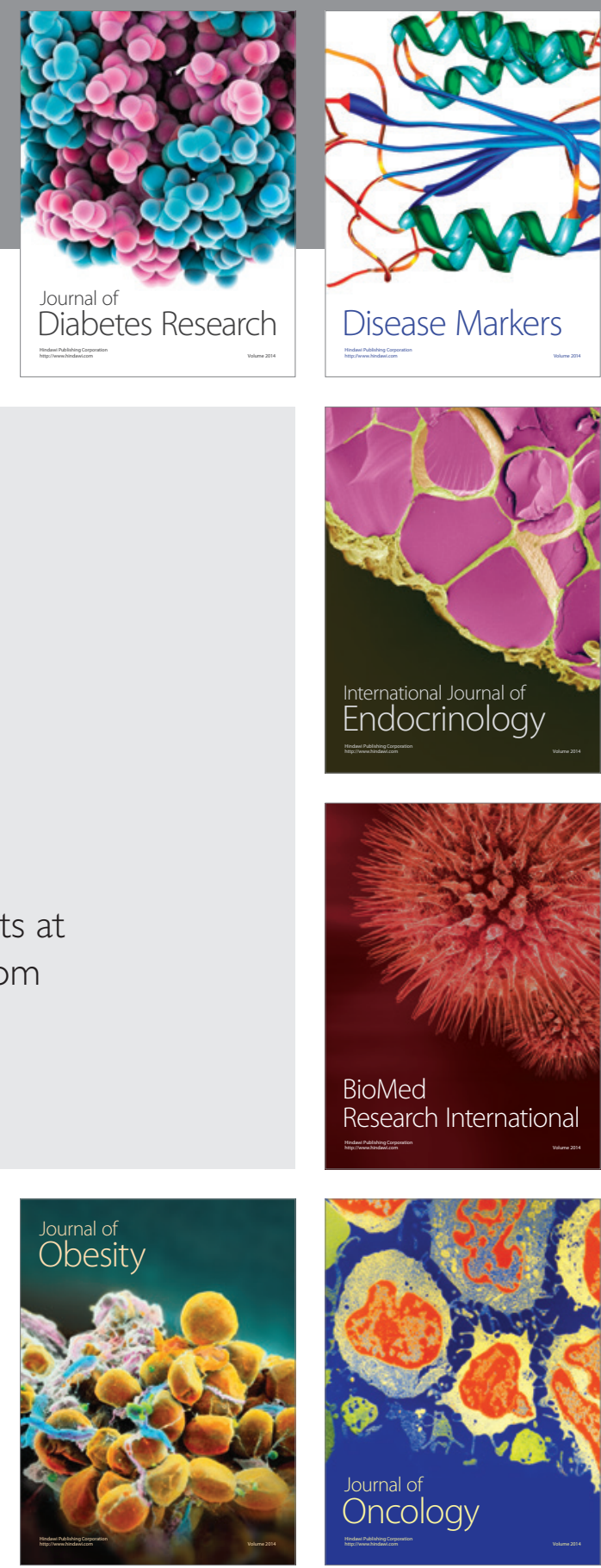

Disease Markers
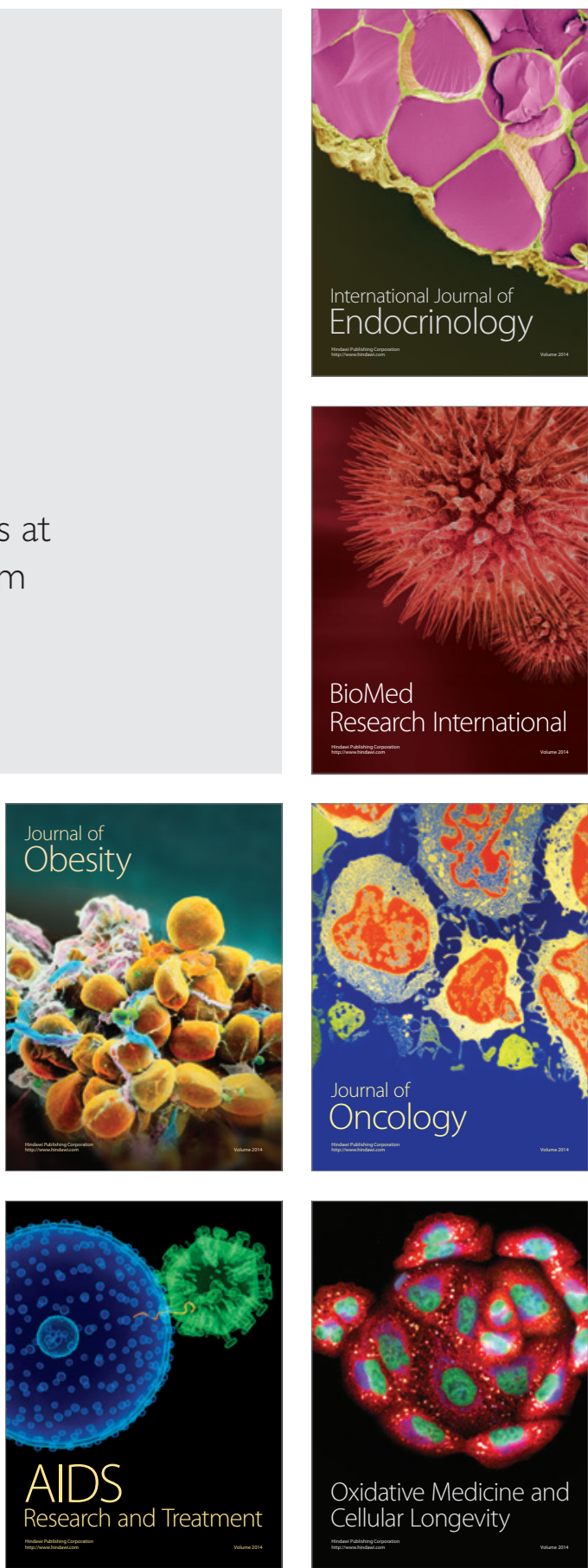